\title{
Snow removal maintained a high level of physical activity in patients undergoing hemodialysis in heavy snowfall areas
}

\author{
Yoichi Sato ${ }^{1,2^{*}}$ (D) and Noriaki lino ${ }^{3}$
}

\begin{abstract}
Background: Physical activity is an essential parameter associated with the prognosis of hemodialysis patients. Physical activity has regional characteristics; for example, snow removal is imperative in snowbelts during the winter. This study investigated the effects of removing snow on the physical activity levels of hemodialysis patients living in a snowbelt.
\end{abstract}

Methods: This study retrospectively examined 28 patients who underwent hemodialysis (age 69.6 \pm 15.4 years, 19 males) in Uonuma Kikan Hospital between December 2019 and March 2020. Physical activity was assessed using the International Physical Activity Questionnaire. Patients were divided into a snow remover group and a non-snow remover group. We examined whether there were differences in physical or mental functioning and physical activity between the two groups. We also investigated the factors that influence high levels of physical activity among hemodialysis patients using multivariate linear regression analysis.

Results: The snow remover group had significantly greater grip strength, higher sit-to-stand test scores and gait speed, and a lower prevalence of frailty than the non-snow remover group. The level of physical activity was also significantly higher in the snow remover group. One of the patients in the snow remover group was frail. The univariate linear regression analysis showed that physical activity was related to age, grip strength, sit-to-stand test score, gait speed, and snow removal. In the multivariate linear regression analysis, snow removal and grip strength were significantly associated with a high level of physical activity.

Conclusions: Among hemodialysis patients living in a snowbelt, the snow remover group had significantly better physical functioning and a higher level of physical activity.

Keywords: Hemodialysis, Physical activity, Snow removal, Heavy snowfall area

\section{Introduction}

Despite advances in dialysis technology and disease management, the mortality rate of hemodialysis patients remains high [1]. There is a close relationship between mortality and low physical activity among hemodialysis

\footnotetext{
* Correspondence: yoichi3041@gmail.com

'Department of Rehabilitation, Uonuma Kikan Hospital, 4132 Urasa, Minamiuonuma 949-7302, Japan

${ }^{2}$ Department of Internal Medicine and Rehabilitation Science, Tohoku University Graduate School of Medicine, Sendai, Japan

Full list of author information is available at the end of the article
}

patients [2], and increasing physical activity leads to an improved prognosis [1]. A previous study reported that hemodialysis patients engage in less physical activity than healthy subjects [3], and interventions to increase physical activity are needed.

It has been reported that parameters of physical functioning such as muscle strength [4] and muscle mass [5] are related to physical activity. Physical activity also has regional characteristics [6]. For example, in snowbelts, snow removal is an essential physical activity during the

C C The Author(s). 2021 Open Access This article is licensed under a Creative Commons Attribution 4.0 International License, which permits use, sharing, adaptation, distribution and reproduction in any medium or format, as long as you give appropriate credit to the original author(s) and the source, provide a link to the Creative Commons licence, and indicate if changes were made. The images or other third party material in this article are included in the article's Creative Commons licence, unless indicated otherwise in a credit line to the material. If material is not included in the article's Creative Commons licence and your intended use is not permitted by statutory regulation or exceeds the permitted use, you will need to obtain permission directly from the copyright holder. To view a copy of this licence, visit http://creativecommons.org/licenses/by/4.0/ The Creative Commons Public Domain Dedication waiver (http://creativecommons.org/publicdomain/zero/1.0/) applies to the data made available in this article, unless otherwise stated in a credit line to the data. 
winter. However, to our knowledge, no studies have examined the effects of snow removal on the level of physical activity among hemodialysis patients.

The Uonuma area in Niigata Prefecture is one of Japan's primary snowbelts and has been designated a particularly heavy snowfall area by the Act on Special Measures Concerning Heavy Snowfall Areas [7]. The annual average amount of snow exceeds $1.3 \mathrm{~m}$ [8]. Moreover, depopulation is occurring in this area, and the number of individuals living alone is increasing. Many people have to remove snow by themselves, including some dialysis patients. In this context, the purpose of this study was to examine the effect of snow removal on hemodialysis patients' level of physical activity in a snowbelt. We believe that this study could provide information that could be useful for managing the physical activity of hemodialysis patients in snowbelts.

\section{Methods}

\section{Study subjects}

This study retrospectively enrolled 33 patients who underwent hemodialysis from December 2019 to March 2020 in Uonuma Kikan Hospital. All subjects lived in the Uonuma area in Niigata Prefecture (Minami Uonuma City, Uonuma City). Patients who had unstable arrhythmia $(n=0)$, unstable hypertension $(n=0)$, or were unable to walk $(n=5)$ were excluded. A total of 28 patients were eligible for study enrollment. After registration, the same examiner evaluated the participants' characteristics. This study was conducted in accordance with the principles of the Declaration of Helsinki and was approved by the Ethics Committee of Uonuma Kikan Hospital (no. 30-056). Participants were given the opportunity to opt out of this study.

\section{Clinical characteristics}

The participants' age, sex, time on dialysis, body mass index (BMI), and family structure were collected from the medical records. In addition, the underlying etiology of dialysis, comorbidities, and levels of hemoglobin, serum albumin, and C-reactive protein were also collected from the medical records.

\section{Snow removal activity}

Based on a previous study [9], participants were asked whether they removed snow during the winter. Those who answered "yes" were defined as "snow removers." The frequency, duration, and area of snow removal were not specified. We asked about the removal of snow within the last year to limit the period.

\section{Evaluations of physical and mental functioning}

The participants' grip strength, sit-to-stand test (STS) score, and gait speed were evaluated as recommended in the renal rehabilitation guidelines [10] and described in previous studies [11, 12]. The STS score is the time needed to stand up from the seated position five times and is included in the short physical performance battery [12]. Gait speed was defined as the speed at which each participant felt comfortable walking. A multifrequency bioelectrical impedance device (InBody S10, Biospace, Japan) was used to estimate muscle mass. The skeletal muscle index (SMI) was calculated as follows: $\mathrm{SMI}=$ lean muscle mass $/$ height $^{2}$ [11]. The estimated muscle mass was measured within $30 \mathrm{~min}$ after dialysis. Frailty was evaluated using the J-CHS Index [13]. Frailty was diagnosed if a participant met three or more of the following criteria: weight loss, weakness, exhaustion, slowness, and low physical activity level. The Patient Health Questionnaire (PHQ)-9 was used to screen for depression [14].

\section{Physical activity}

We used the International Physical Activity Questionnaire (IPAQ) - Short Form to evaluate physical activity. The IPAQ has been recognized worldwide for its reliability and validity [15]. The usefulness of this questionnaire for the evaluation of physical activity in Japanese populations has been reported [16]. The amounts of physical activity performed that was categorized as high intensity, moderate intensity, and mild intensity were calculated based on the methods described in a previous study [16]. The sum of patient-reported activities according to the IPAQ was defined as the total physical activity level, and the metabolic equivalent of task (MET) score per week (MET-min/week) was calculated. The sum of the time spent engaged in moderate- and highintensity activity was defined as moderate-to-vigorous intensity physical activity (MVPA).

\section{Statistical analysis}

A chi-squared test was used to compare categorical variables between the snow remover group and the nonsnow remover group. An unpaired $t$ test was used to analyze continuous variables. A univariate linear regression analysis was performed with physical activity as the dependent variable. The variables that were significant in the univariate regression analysis were used as independent variables in a multivariate linear regression analysis. The presence or absence of snow removal was used as a dummy variable. All statistical tests were performed using SPSS version 21.0 (IBM Corp., Japan). $P$ values less than 0.05 were considered to indicate statistical significance.

\section{Results}

We collected the temperature, wind speed, precipitation, and snowfall information in the Uonuma area from December 2019 to March 2020 (Table 1). The 
Table 1 Meteorological data for the Uonuma area in winter

\begin{tabular}{llll}
\hline Average temperature $\left({ }^{\circ} \mathrm{C}\right)$ & Average precipitation $(\mathbf{m m})$ & Average wind velocity $(\mathrm{m} / \mathbf{s})$ & Average snowfall $(\mathbf{c m})$ \\
\hline $2.5 \pm 3.2$ & $5.4 \pm 6.3$ & $2.1 \pm 0.9$ & $6.1 \pm 5.6$ \\
\hline
\end{tabular}

This data is the average from December 2019 to March 2020. Values are means \pm standard deviation

information is posted on the Japan Meteorological Agency Website [17]. During this period, there was less snow than usual for the time of year.

\section{Patient characteristics}

Table 2 shows the clinical characteristics of the patients. After applying the exclusion criteria, 28 patients were included. Ten patients performed snow removal. There were no significant differences between the two groups in age, sex, BMI, time on dialysis, or levels of hemoglobin, serum albumin, or C-reactive protein. Two patients were living alone, and they removed the snow by themselves.

\section{Physical and mental functioning}

Table 3 shows the physical and mental functioning of the two groups. The snow remover group had significantly greater grip strength and higher STS score and gait speed $(p=0.028, p=0.015$, and $p=0.038$, respectively). Among all the patients, $42.9 \%$ were frail, and significantly fewer patients were frail in the snow remover group than in the non-snow remover group $(p=0.011)$. One of the patients who performed snow removal was frail, and he lived alone. There was no significant difference in the SMI and PHQ-9 scores between the two groups.

\section{Effect of each index on physical activity}

Table 4 shows the results of the univariate and multivariate linear regression analysis for total physical activity. The univariate linear regression analysis showed that physical activity was related to age, grip strength, STS score, gait speed, and snow removal $(p=0.003, p=$ $0.016, p=0.024, p=0.044$, and $p=0.001$, respectively). For the variables that were significant in the univariate linear regression analysis, the correlation coefficients were calculated to confirm the multicollinearity. As a result, strong correlations were found between grip strength and STS score $(r=-0.821, p<0.001)$, between grip strength and gait speed $(r=0.809, p<0.001)$, and between STS score and gait speed $(r=-0.827, p<$ 0.001). Therefore, we used grip strength as an independent variable, and grip strength was reported in a previous study as being related to physical activity [4]. The STS score and gait speed were excluded. The multivariate linear regression analysis was performed using age, grip strength, and snow removal as independent variables. Physical activity was the dependent variable. Grip strength and snow removal were associated with physical activity ( $p=0.035$ and $p=0.002$, respectively). That is, patients with stronger grip strength who also performed snow removal had a higher level of physical activity. However, the adjusted $R^{2}$ value was 0.41 . Physical activity may be affected by other factors. Table 5 shows the results of the univariate and multivariate linear regression analyses for MVPA. Age, grip strength, and snow removal were independently associated with MVPA ( $p=$ $0.023, p=0.021$, and $p=0.005$, respectively). The adjusted $R^{2}$ value was 0.58 . The adjusted $R^{2}$ for MVPA was better than that for total physical activity.

\section{Discussion}

It is important to consider regional characteristics to improve the level of physical activity of hemodialysis patients. In snowbelt regions, snow removal during the winter is a common and essential physical activity. However, there has been no previous study on the effect of snow removal on hemodialysis patients' level of physical activity.

The median level of physical activity of hemodialysis patients was 993 MET-minutes/week. Among 320 Chinese dialysis patients with an average age of 58 years, the median physical activity level was $1533 \mathrm{MET}$-min/week [18]. The patients in the present study were relatively inactive compared to those in previous studies. The average age of patients in this study was 69.6 years, which is older than patients in previous studies. The univariate linear regression analysis showed that age was associated with physical activity. The older age of participants in this study compared with participants in previous studies may be associated with the lower activity level of our participants. In addition, physical activity levels tend to decrease in the winter, which was when this study took place [19-21]. Thus, regionality, age, and season must be taken into account when examining physical activity.

The snow remover group had a high physical activity level with good physical function in terms of grip strength, STS score, and gait speed. To our knowledge, there are no reports that snow removal has improved physical functioning. However, previous studies have reported that there is a positive correlation between physical functioning and physical activity in healthy subjects $[4,5]$, which is also supported by the present study. In healthy subjects, snow removal is associated with high physical activity levels [22]. In this study, snow removal was associated with MVPA in hemodialysis patients. Exercise therapy is recommended for hemodialysis patients to improve exercise tolerance, walking ability, and quality of life [10]. The guidelines for renal rehabilitation 
Table 2 Demographic characteristics

\begin{tabular}{|c|c|c|c|c|}
\hline & All patient $(n=28)$ & Snow remover $(n=10)$ & Non-snow remover $(n=18)$ & $p$ value \\
\hline Age (years) & $69.6 \pm 15.4$ & $64.6 \pm 13.9$ & $72.4 \pm 15.9$ & 0.191 \\
\hline Men & $19(67.9)$ & $8(80.0)$ & $10(55.6)$ & 0.190 \\
\hline BMI $\left(\mathrm{kg} / \mathrm{m}^{2}\right)$ & $23.0 \pm 4.5$ & $23.7 \pm 3.5$ & $22.6 \pm 5.1$ & 0.504 \\
\hline \multicolumn{5}{|l|}{ Original disease $(n)$} \\
\hline Diabetic nephropathy & $10(35.7)$ & $5(50.0)$ & $5(27.8)$ & \\
\hline Hypertensive nephrosclerosis & $7(25.0)$ & $3(30.0)$ & $4(22.2)$ & \\
\hline Chronic glomerulonephritis & $4(14.3)$ & $0(0.0)$ & $4(22.2)$ & \\
\hline Other & $5(17.9)$ & $1(10.0)$ & $4(22.2)$ & \\
\hline Unknown & $2(7.1)$ & $1(10.0)$ & $1(5.6)$ & \\
\hline Time on dialysis (years) & $7.4 \pm 8.6$ & $8.2 \pm 11.6$ & $6.8 \pm 6.8$ & 0.740 \\
\hline \multicolumn{5}{|l|}{ Comorbidities ( $n$ ) } \\
\hline Hypertension & $24(85.7)$ & $8(80.0)$ & $16(88.9)$ & \\
\hline Diabetes mellitus & $13(46.4)$ & $6(60.0)$ & $7(38.9)$ & \\
\hline Chronic heart failure & $8(28.6)$ & $4(40.0)$ & $4(22.2)$ & \\
\hline Dyslipidemia & $6(21.4)$ & $3(30.0)$ & $3(16.7)$ & \\
\hline Ischemic heart disease & $4(14.3)$ & $3(30.0)$ & $1(5.6)$ & \\
\hline Cerebrovascular disease & $2(7.1)$ & $0(0.0)$ & $2(11.1)$ & \\
\hline \multicolumn{5}{|l|}{ Household } \\
\hline Alone $(n)$ & $2(7.1)$ & $2(20.0)$ & $0(0.0)$ & 0.119 \\
\hline \multicolumn{5}{|l|}{ Blood laboratory data } \\
\hline Hemoglobin (mg/dl) & $11.1 \pm 0.8$ & $11.3 \pm 0.7$ & $11.0 \pm 0.8$ & 0.293 \\
\hline Serum albumin (mg/dl) & $3.5 \pm 0.4$ & $3.5 \pm 0.4$ & $3.6 \pm 0.4$ & 0.630 \\
\hline C-reactive protein (mg/dl) & $0.5 \pm 0.7$ & $0.8 \pm 1.0$ & $0.3 \pm 0.5$ & 0.102 \\
\hline
\end{tabular}

Values are means \pm standard deviation or number of subjects per group $(n)$ with percentages

$B M I$ body mass index

Table 3 Clinical characteristics

\begin{tabular}{|c|c|c|c|c|}
\hline & All patients $(n=28)$ & Snow remover $(n=10)$ & Non-snow remover $(n=18)$ & $p$ value \\
\hline \multicolumn{5}{|l|}{ Physical function } \\
\hline Grip strength (kg) & $20.7 \pm 9.1$ & $23.8 \pm 7.8$ & $19.6 \pm 9.6$ & 0.028 \\
\hline STS (s) & $13.8 \pm 8.4$ & $9.7 \pm 1.0$ & $16.0 \pm 9.8$ & 0.015 \\
\hline Gait speed (m/s) & $1.0 \pm 0.3$ & $1.2 \pm 0.2$ & $1.0 \pm 0.3$ & 0.038 \\
\hline $\mathrm{SMI}\left(\mathrm{kg} / \mathrm{m}^{2}\right)$ & $6.1 \pm 0.7$ & $6.1 \pm 0.4$ & $6.2 \pm 0.8$ & 0.719 \\
\hline Frailty $(n)$ & $12(42.9)$ & $1(10.0)$ & $11(61.1)$ & 0.011 \\
\hline \multicolumn{5}{|l|}{ Mental function } \\
\hline PHQ-9 (point) & $7.3 \pm 4.4$ & $8.5 \pm 5.9$ & $6.7 \pm 3.4$ & 0.383 \\
\hline \multicolumn{5}{|l|}{ Physical activity } \\
\hline Total activity (MET-min/week) & $993(1243)$ & $1939(800)$ & $693(463)$ & 0.005 \\
\hline MVPA (MET-min/week) & $300(580)$ & $640(680)$ & $90(180)$ & 0.003 \\
\hline
\end{tabular}

Values are means \pm standard deviation or number of subjects per group $(n)$ with percentages. Total activity is median (interquartile range)

STS sit-to-stand test, SMI Skeletal Muscle Index, PHQ-9 Patient Health Questionnaire-9, MVPA moderate-to-vigorous physical activity 
Table 4 Predictors of total physical activity

\begin{tabular}{|c|c|c|c|c|c|c|}
\hline \multirow[t]{3}{*}{ Variable } & \multicolumn{6}{|c|}{ Total physical activity } \\
\hline & \multicolumn{3}{|c|}{ Univariate analysis } & \multicolumn{3}{|c|}{ Multivariate analysis } \\
\hline & $B(\mathrm{SE})$ & $95 \% \mathrm{Cl}$ for $B$ & $p$ value & $B(\mathrm{SE})$ & $95 \% \mathrm{Cl}$ for $B$ & $p$ value \\
\hline Age & $-30.2(9.3)$ & -49.4 to -11.0 & 0.003 & $-14.6(8.8)$ & -32.7 to 3.6 & 0.11 \\
\hline Gender & $345.9(342.2)$ & -357.4 to 1049.2 & 0.321 & & & \\
\hline BMl & $87.4(33.5)$ & -18.6 to 156.2 & 0.065 & & & \\
\hline Dialysis duration & $-11.0(19.6)$ & -51.3 to 29.3 & 0.579 & & & \\
\hline Hemoglobin & $214.8(215.6)$ & -228.5 to 658.1 & 0.328 & & & \\
\hline Serum albumin & $940.0(444.9)$ & -25.5 to 1854.5 & 0.064 & & & \\
\hline C-reactive protein & $53.0(235.7)$ & -431.5 to 537.4 & 0.824 & & & \\
\hline Grip strength & $43.0(16.7)$ & 8.7 to 77.3 & 0.016 & $32.1(14.4)$ & 2.4 to 61.7 & 0.035 \\
\hline STS & $-44.1(18.4)$ & -81.8 to -6.3 & 0.024 & & & \\
\hline Gait speed & $1282.9(486.3)$ & 283.4 to 2282.5 & 0.044 & & & \\
\hline SMI & $124.3(71.2)$ & -22.3 to 270.6 & 0.930 & & & \\
\hline PHQ-9 & $10.0(38.3)$ & -68.7 to 88.7 & 0.797 & & & \\
\hline Snow removal & $1052.3(281.2)$ & 474.2 to 1630.3 & 0.001 & 919.2 (268.8) & 365.7 to 1472.8 & 0.002 \\
\hline
\end{tabular}

SE standard error, Cl confidence interval, STS sit-to-stand test, SMI Skeletal Muscle Index, PHQ-9 Patient Health Questionnaire-9

recommend both aerobic exercise and resistance training [10]. Furthermore, a high physical activity level leads to decreased mortality in hemodialysis patients $[1,2]$. Thus, it is suggested that maintaining physical activity by removing snow could be important for patient management in snowbelts.

One of the patients who performed snow removal was frail. This patient lived alone and had to remove snow by himself. The oxygen uptake $\left(\mathrm{VO}_{2}\right)$ of healthy males who removed snow using a shovel was $63 \%$ of the maximum $\mathrm{VO}_{2}$ [23], which corresponds to moderateintensity exercise. In addition, the exercise load of those who used snow pushers was even higher. In the present study, we did not ask about the method of snow removal. However, snow removal and MVPA were independently related. If a patient's physical strength decreases, the exercise load may increase. It has been reported that physical inactivity is related to cardiac events

Table 5 Predictors of MVPA

\begin{tabular}{|c|c|c|c|c|c|c|}
\hline \multirow[t]{3}{*}{ Variable } & \multicolumn{6}{|l|}{ MVPA } \\
\hline & \multicolumn{3}{|c|}{ Univariate analysis } & \multicolumn{3}{|c|}{ Multivariate analysis } \\
\hline & $B(\mathrm{SE})$ & $95 \% \mathrm{Cl}$ for $B$ & $p$ value & $B(\mathrm{SE})$ & $95 \% \mathrm{Cl}$ for $B$ & $p$ value \\
\hline Age & $-19.3(5.2)$ & -29.1 to -8.6 & 0.001 & $-11.2(4.6)$ & -20.6 to -1.7 & 0.023 \\
\hline Gender & $263.4(195.7)$ & -138.8 to 665.7 & 0.190 & & & \\
\hline BMl & $34.6(20.7)$ & -8.0 to 77.2 & 0.107 & & & \\
\hline Dialysis duration & $-3.7(11.4)$ & -27.2 to 19.7 & 0.746 & & & \\
\hline Hemoglobin & $150.0(124.0)$ & -104.9 to 405.0 & 0.237 & & & \\
\hline Serum albumin & $721.3(241.0)$ & -26.0 to 1216.7 & 0.096 & & & \\
\hline C-reactive protein & $4.6(136.9)$ & -236.8 to 285.9 & 0.974 & & & \\
\hline Grip strength & $32.2(8.8)$ & 14.0 to 50.3 & 0.001 & $19.1(7.7)$ & 3.2 to 35.0 & 0.021 \\
\hline STS & $-25.8(10.6)$ & -47.6 to -3.9 & 0.023 & & & \\
\hline Gait speed & $864.3(268.7)$ & 312.0 to 1416.6 & 0.003 & & & \\
\hline SMI & $73.1(41.3)$ & -11.7 to 157.9 & 0.088 & & & \\
\hline PHQ-9 & $1.8(22.2)$ & -43.9 to 47.5 & 0.936 & & & \\
\hline Snow removal & $581.2(167.2)$ & 237.5 to 925.0 & 0.002 & $415.2(133.8)$ & 139.0 to 691.4 & 0.005 \\
\hline
\end{tabular}

Model $R^{2}=0.63$, adjusted $R^{2}=0.58$, intercept $=715.3$

MVPA moderate-to-vigorous physical activity, SE standard error, Cl confidence interval, STS sit-to-stand test, SMI Skeletal Muscle Index, PHQ-9 Patient Health Questionnaire-9 
during snow removal [24]. In addition, many accidents involving falling while removing snow from a rooftop are reported every year [8]. Snow removal may be a hazardous activity when performed by people with poor physical function. Snow removal is a necessary activity during the winter, but whether it is feasible for an individual patient to engage in it should be determined based on the consideration of that patient's physical strength and social background. There are various types of administrative support available with regard to snow removal for elderly individuals living alone, although none of the patients in this study accessed such forms of administrative support. For example, there is a subsidy for outsourcing snow removal to a company. Medical staff members should consider proposing such services as appropriate.

This study has several limitations. First, we did not ask about the duration and frequency of snow removal. A detailed evaluation of how snow removal is performed is needed. Furthermore, because this study enrolled hemodialysis patients in a snowbelt area, the results are not directly applicable to patients in other areas. The amount of snowfall in 2020 was lower than usual, which may have affected the results. Another limitation is that physical activity was evaluated using a questionnaire. In recent years, many studies have evaluated physical activity using accelerometers. Thus, it is necessary to perform a more objective evaluation in future studies. This study was a cross-sectional study based on evaluations performed during the winter and did not examine the effects of activity during the summer. The relationship between snow removal and physical activity in the summer has not been studied. And, the sample size was small, and in the multivariate linear regression analysis, the adjusted $R^{2}$ value was 0.41 . Therefore, it is necessary to examine factors that directly influence physical activity. Lastly, this study is a cross-sectional study and does not provide any information regarding "cause and effect relationship" between snow removal habit and higher physical function. This study might only reflect the present condition that "subjects with poorer physical ability are not able to perform snow removal." Therefore, a prospective cohort study needs to clarify the relationship between snow removal habit and physical function.

\section{Conclusion}

Hemodialysis patients living in a snowbelt who performed snow removal maintained high physical activity levels and adequate physical functioning, such as grip strength. However, some frail patients have to remove snow by themselves because they live alone. Because snow removal is a high-intensity activity, it is necessary to evaluate patients' physical functioning and social context and to pay attention to the possibility of overexertion.

\section{Abbreviations}

BMI: Body mass index; STS: Sit-to-stand test; SMl: Skeletal muscle index; PHQ9: Patient Health Questionnaire-9; IPAQ: International Physical Activity Questionnaire; $\mathrm{VO}_{2}$ : Oxygen uptake; MVPA: Moderate-to-vigorous intensity physical activity

\section{Acknowledgements}

We would like to thank the staff at the Hemodialysis Center of Uonuma Kikan Hospital who supported this study. We thank Kazuki Hotta (Niigata University of Health and Welfare) and Chiharu Hotta (Niigata University Medical and Dental Hospital) for helping draft the manuscript. We would like to thank American Journal Experts (https://www.aje.com/) for editing a draft of this manuscript.

\section{Authors' contributions}

YS was involved in the study design and in the writing of the manuscript. YS participated in the study procedure implementation and data collection. NI reviewed and revised the manuscript. All authors read and approved the final manuscript.

Funding

Not applicable.

\section{Availability of data and materials}

The datasets used and analyzed in this study are available from the corresponding author upon reasonable request.

\section{Declarations}

Ethics approval and consent to participate

The institutional review board of the ethics committee at Uonuma Kikan Hospital approved the study protocol (no. 30-056), and the study was conducted according to the principles of the Declaration of Helsinki.

\section{Consent for publication}

Not applicable.

\section{Competing interests}

The authors declare that they have no competing interests.

\section{Author details}

'Department of Rehabilitation, Uonuma Kikan Hospital, 4132 Urasa, Minamiuonuma 949-7302, Japan. '2Department of Internal Medicine and Rehabilitation Science, Tohoku University Graduate School of Medicine, Sendai, Japan. ${ }^{3}$ Department of Nephrology, Uonuma Institute of Community Medicine, Niigata University Medical and Dental Hospital, Niigata, Japan.

Received: 9 May 2020 Accepted: 21 February 2021

Published online: 02 March 2021

\section{References}

1. Shimoda T, Matsuzawa R, Yoneki K, Harada M, Watanabe T, Matsumoto M, et al. Changes in physical activity and risk of all-cause mortality in patients on maintence hemodialysis: a retrospective cohort study. BMC Nephrol. 2017;18:154.

2. Matsuzawa R, Roshanravan B, Shimoda T, Mamorita N, Yoneki K, Harada M, et al. Physical activity dose for hemodialysis patients: where to begin? Results from a prospective cohort study. J Ren Nutr. 2018;28:45-53.

3. Johansen $\mathrm{KL}$, Chertow GM, Ng AV, Mulligan $\mathrm{K}$, Carey $\mathrm{S}$, Schoenfeld PY, et al. Physical activity levels in patients on hemodialysis and healthy sedentary controls. Kidney Int. 2000;57:2564-70.

4. Souweine JS, Kuster N, Chenine L, Rodriguez A, Patrier L, Morena M, et al. Physical inactivity and protein energy wasting play independent roles in muscle weakness in maintenance haemodialysis patients. PLoS One. 2018; 13:e0200061.

5. Morishita Y, Kubo K, Miki A, Ishibashi K, Kusano E, Nagata D. Positive association of vigorous and moderate physical activity volumes with skeletal muscle mass but not bone density or metabolism markers in hemodialysis patients. Int Urol Nephrol. 2014;46:633-9.

6. Levine JA, McCrady SK, Boyne S, Smith J, Cargill K, Forrester T. Non-exercise physical activity in agricultural and urban people. Urban Stud. 2011;48:2417-27. 
7. Ministry of Land, Infrastructure, transport and tourism: designated areas with heavy snowfall areas and special heavy snowfall areas. http://www.mlit.go. jp/kokudoseisaku/chisei/crd_chisei_tk_000010.html. [in Japanese]. Accessed 8 May 2020.

8. Yamaguchi S, Endoh $\mathrm{H}$, Nitta M. Accidental falls related to clearing heavy snow on rooftops in a rural heavy snow area in Japan. Acute Med Surg. 2016;:166-71.

9. Mizumoto A, Ihira H, Makino K, Saitoh S, Ohnishi H, Furuna T. Physical activity changes in the winter in older persons living in northern Japan: a prospective study. BMC Geriatr. 2015;15:43.

10. Yamagata K, Hoshino J, Sugiyama H, Hanafusa N, Shibagaki Y, Komatsu Y, et al. Clinical practice guideline for renal rehabilitation: systematic reviews and recommendations of exercise therapies in patients with kidney diseases. Ren Replace Ther. 2019;5:28.

11. Hotta C, Hiraki K, Wakamiya A, Otobe Y, Watanabe S, Izawa KP, et al. Relation of physical function and physical activity to sarcopenia in hemodialysis patients: a preliminary study. Int J Cardiol. 2015;191:198-200

12. Ortega-Pérez de Villar L, Martínez-Olmos FJ, Junqué-Jiménez A, et al. Testretest reliability and minimal detectable change scores for the short physical performance battery, one-legged standing test and timed up and go test in patients undergoing hemodialysis. PLoS One. 2018;13:e0201035.

13. Satake S, Shimada H, Yamada M, Kim H, Yoshida H, Gondo Y, et al. Prevalence of frailty among community-dwellers and outpatients in Japan as defined by the Japanese version of the Cardiovascular Health Study criteria. Geriatr Gerontol Int. 2017;17:2629-34.

14. Shirazian S, Grant CD, Aina O, Mattana J, Khorassani F, Ricardo AC Depression in chronic kidney disease and end-stage renal disease: similarities and differences in diagnosis, epidemiology, and management. Kidney Int Rep. 2016;2:94-107.

15. Craig CL, Marshall AL, Sjöström M, Bauman AE, Booth ML, Ainsworth BE, et al. International physical activity questionnaire: 12-country reliability and validity. Med Sci Sports Exerc. 2003;35:1381-95.

16. Tomioka K, Iwamoto J, Saeki K, Okamoto N. Reliability and validity of the International Physical Activity Questionnaire (IPAQ) in elderly adults: the Fujiwara-kyo Study. J Epidemiol. 2011;21:459-65.

17. Japan Meteorological Agency: Meteorological observation data. http://www. fdma.go.jp/bn/2012/detail/739.html. [in Japanese]. Accessed 8 May 2020

18. Lou X, He Q. Validity and reliability of the International Physical Activity Questionnaire in Chinese hemodialysis patients: a multicenter study in China. Med Sci Monit. 2019;25:9402-8.

19. Hasegawa J, Suzuki H, Yamauchi T. Impact of season on the association between muscle strength/volume and physical activity among communitydwelling elderly people living in snowy-cold regions. J Physiol Anthropol. 2018;37:25.

20. Klompstra L, Jaarsma T, Strömberg A, van der Wal MHL. Seasonal variation in physical activity in patients with heart failure. Heart Lung. 2019;48:381-5.

21. Ogawa S, Seko T, Ito T, Mori M. Differences in physical activity between seasons with and without snowfall among elderly individuals residing in areas that receive snowfall. J Phys Ther Sci. 2019;31:12-6.

22. Chan CB, Ryan DA. Assessing the effects of weather conditions on physical activity participation using objective measures. Int I Environ Res Public Health. 2009;6:2639-54.

23. Smolander J, Louhevaara V, Ahonen E, Polari J, Klen T. Energy expenditure and clearing snow: a comparison of shovel and snow pusher. Ergonomics. 1995;38:749-53.

24. Franklin BA, George P, Henry R, Gordon S, Timmis GC, O'Neill WW. Acute myocardial infarction after manual or automated snow removal. Am J Cardiol. 2001;87:1282-3.

\section{Publisher's Note}

Springer Nature remains neutral with regard to jurisdictional claims in published maps and institutional affiliations.

Ready to submit your research? Choose BMC and benefit from:

- fast, convenient online submission

- thorough peer review by experienced researchers in your field

- rapid publication on acceptance

- support for research data, including large and complex data types

- gold Open Access which fosters wider collaboration and increased citations

- maximum visibility for your research: over $100 \mathrm{M}$ website views per year

At BMC, research is always in progress.

Learn more biomedcentral.com/submissions 